\title{
Analysis of the acceptance of park-and-ride by users: A cumulative logistic regression approach
}

\author{
Kai Huang \\ Southeast University \\ Monash University \\ Kai.huang@monash.edu \\ Ting Zhu \\ Southeast University \\ 549224276@qq.com

\section{Kun An} \\ Monash University \\ kun.an@monash.edu
}

\author{
Zhiyuan Liu (corresponding author) \\ Southeast University \\ zhiyuanl@seu.edu.cn \\ Inhi Kim \\ Monash University \\ inhi.Kim@monash.edu
}

\begin{abstract}
Park-and-ride (P\&R) schemes are an important way of increasing the public transport mode share, which relieves the negative impact caused by excessive automobile usage. Several existing studies have been conducted in the past to explore the factors that can influence the acceptance of $P \& R$ by travelers. However, quantitative analyses of the pertinent factors and rates of traveler choice are quite rare. In this paper, the data collected from a survey in Melbourne, Australia, is used to analyze the acceptance of $P \& R$ by travelers going to the central business district (CBD). In particular, we explore the influence that specific factors have on the choice of travel by those who are currently using $\mathrm{P} \& \mathrm{R}$. The results indicate that the parking fee in the CBD area, travel time on public transport, and $P \& R$ transfer time affect traveler use of $\mathrm{P} \& \mathrm{R}$. A quantitative assessment of the impact of these three factors is conducted by using a cumulative logistic regression model. Results reveal that the $P \& R$ transfer time has the highest sensitivity while public transport travel time has the least. To maximize the use of $P \& R$ facilities and public transport, insights into setting parking fees and designing $\mathrm{P} \& \mathrm{R}$ stations are presented.
\end{abstract}

\section{Introduction}

\subsection{Background}

The rapid expansion of privately-owned vehicles and comparatively limited road space have caused serious traffic congestion and environmental pollution problems in most developing countries (Dijk, de Haes, \& Montalvo,2013; Wang, 2013; Huang, Correia, \& An, 2018; Liu, Wang, Huang, Chen, \& $\mathrm{Fu}, 2019)$. In addition, in some developed countries like Australia, the residential density is too low to

Copyright 2019 Kai Huang, Zhiyuan Liu, Ting Zhu, Inhi Kim, \& Kun An

http://dx.doi.org/10.5198/jtlu.2019.1390

ISSN: 1938-7849 | Licensed under the Creative Commons Attribution - Noncommercial License 4.0

The Journal of Transport and Land Use is the official journal of the World Society for Transport and Land Use (WSTLUR) and is published and sponsored by the University of Minnesota Center for Transportation Studies.

Article history:

Received: March 5, 2018

Received in revised form:

March 11, 2019

Accepted: July 18, 2019

Available online: July 30, 2019 
support adequate feeder services for travelers. It is more obvious in suburban areas. Park and ride (P\&R) is viewed as an important part of the solution to this problem (Liu \& Meng, 2012; Yan, Delmelle, \& Duncan, 2012; Qin, Guan, \& Wu, 2013). It has attracted lots of attention of transport engineers, transit operators, and urban planners. A high frequency of public transport services, shorter transfer time, and a reasonable fare structure can all be seen to be common measures that can be used to promote the mode share of $P \& R$.

In the $P \& R$ scheme, rather than driving to the city center directly, travelers could park their cars in peripheral cities or towns and then head into the city center using public transport, e.g. a light rail or metro line (Karamychev \& van Reeven, 2011). P\&R has the merits of concentrating transit rider demand, expanding the reach of transit into low-density areas, reducing parking demand in the Central Business District (CBD), and reducing inner city street congestion, etc. (Evans \& Pratt, 2003). In general, the P\&R scheme has two important functions (Wang, Yang, \& Lindsey, 2004). Firstly, the scheme allows travelers to drive in the uncongested part of their journey and then use public transport in the low speed-limit part of their journey (i.e., the congested part) by facilitating modal shifts. Besides, it helps to reduce traffic congestion by encouraging road users to take public transport as a part of their journey. Therefore, $P \& R$ plays an important role in the procedure of the public transport planning.

However, some studies have found that P\&R might bring lots of negative influences on the sustainable transport systems (Shirgaokar \& Deakin, 2005; Li, Lam, Wong, Zhu, \& Huang, 2007). The arbitrarily planned $P \& R$ can result in the increasing number of trips using private vehicles, the long detour travel distance and high pollution emission (Liu, Chen, Meng, \& Kim, 2018). Besides, the benefits of transit-oriented development in P\&R system easily be over-estimated (Duncan \& Christensen, 2013). Both the need of huge land to build parking spaces and poor environment caused by noise and tail gas have the negative influence on transit-oriented development.

Therefore, in light of the significant role of $P \& R$ in promoting sustainable transport systems, many related studies have been conducted on this mode. However, the effort expended into exploring the factors that might contribute to creating a high-patronage P\&R scheme has been insufficient. Moreover, in the existing studies, the majority of the consider those factors such as the network of P\&R sites, the urban morphology, the incidental services and facilities at the P\&R sites, the ready-availability of travel information, and branding recognition. To the best of our knowledge, no study has focused on the acceptance of P\&R by travelers based on specific market policies and attributes of the facilities.

\subsection{Literature review}

The influence factors of $\mathrm{P} \& \mathrm{R}$ can be broadly divided into two groups: "transportation attributes" and "individual attributes."

The first group (transportation attributes) mainly relates to: the travel costs, public transport total travel time (PTTT), transfer time (TT) at the P\&R station, trip purpose, road congestion, department time, station type and number, as well as trip frequency. In 2008, Hamid, Mohammad, and Karim [1] outlined the behavior of $P \& R$ users via carrying out a questionnaire survey in the conurbation of Kuala Lumpur. They found that the travel time by rail, trip purpose, egress mode, and types of rail fare have the greatest impact on P\&R behavior. By conducting an interview survey of 524 car-owning residents in Shanghai, Ying and Xiang (2009) [2] found that the road congestion and parking policies in the CBD were the main factors of concern to the residents. In 2012, by using a logit regression analysis model, Qin et al. [3] claimed that the total travel time (including driving time, parking time, TT, and PTTT) and the total travel cost (including the travel cost of using their private cars, parking cost, and cost of taking public transport) were the most important factors influencing P\&R choice. The destination of the trip could also affect one's P\&R behavior, to a certain extent. Qin et al. (2013) [4] listed the main 
factors, such as travel time (driving time, TT, and PTTT), travel or parking cost, traffic congestion, and number of transfers, which can be used to study how travelers make choices among the private car, public transport, and P\&R. In 2014, Olaru, Smith, Xia, and Lin [5] identified that the factors that affect the use of $P \& R$ facilities are mainly departure time and road congestion, access time and cost, characteristics of the railway station, and socio-demographics of the travelers. A case study of P\&R in Bath, UK, by Clayton, Ben-Elia, Parkhurst, and Ricci (2014) [6] showed that travel distance and availability of P\&R sites significantly influences the use of $P \& R$, whereas, trip frequency and purpose did not carry much weight in the decision process. Mahmoud, Habib, and Shalaby (2014) [7] realized that the access distance and relative station direction (towards the workplace) affect travelers' mode choices. Furthermore, some quality factors relating to facilities, such as timetables, security, and standard of the transportation system, have also been used as indices to make the model choice (Lindstroem, 2003) [8].

The second group (individual attributes) mainly relates to income, job, age, gender, and environmental awareness. Hamid et al. (2008) [1], Qin, Guan, and Zhang (2012) [3], and Clayton et al. (2014) [6] suggested that the key factors influencing travelers' choice of P\&R are the income, job, age, and gender. In addition, the recognition that $P \& R$ is able to reduce environmental pollution also affects travelers' decisions (Mingardo, 2013) [9]. That is, people tend to choose P\&R if they believe it would improve air quality by reducing harmful emissions such as $\mathrm{CO} 2$ and NOx.

Table 1 shows the issues addressed in each of the studies outlined above more clearly.

Table 1. The influence factors of $P \& R$ users studied by different workers

\begin{tabular}{|c|c|c|c|c|c|c|c|c|c|c|}
\hline \multirow[t]{2}{*}{ Attribute type } & \multirow[t]{2}{*}{ Variable } & \multicolumn{9}{|c|}{ Reference } \\
\hline & & {$[1]$} & [2] & [3] & {$[4]$} & [5] & [6] & [7] & [8] & [9] \\
\hline \multirow{8}{*}{ Transportation } & Travel cost & $\sqrt{ }$ & $\sqrt{ }$ & $\sqrt{ }$ & $\sqrt{ }$ & $\sqrt{ }$ & & $\sqrt{ }$ & $\sqrt{ }$ & \\
\hline & PTTT & $\sqrt{ }$ & & $\sqrt{ }$ & $\sqrt{ }$ & & & & $\sqrt{ }$ & \\
\hline & TT at P\&R station & & & $\sqrt{ }$ & $\sqrt{ }$ & $\sqrt{ }$ & & & $\sqrt{ }$ & \\
\hline & Trip purpose & $\sqrt{ }$ & & $\sqrt{ }$ & & & $\sqrt{ }$ & & $\sqrt{ }$ & \\
\hline & Road congestion & & $\sqrt{ }$ & & $\sqrt{ }$ & $\sqrt{ }$ & & & & \\
\hline & Department time & & & & & $\sqrt{ }$ & & & & \\
\hline & Station type and number & $\sqrt{ }$ & & & & $\sqrt{ }$ & $\sqrt{ }$ & $\sqrt{ }$ & $\sqrt{ }$ & \\
\hline & Trip frequency & & & & & & $\sqrt{ }$ & & & \\
\hline \multirow{5}{*}{ Individual } & Income & $\sqrt{ }$ & & $\sqrt{ }$ & & & $\sqrt{ }$ & & & \\
\hline & Job & & & $\sqrt{ }$ & & & & & & \\
\hline & Age & & & & & & $\sqrt{ }$ & & & \\
\hline & Gender & & & & & & $\sqrt{ }$ & & & \\
\hline & Environmental awareness & & & & & & & & & $\sqrt{ }$ \\
\hline
\end{tabular}

We find the existing studies have the following limitations:

(i) From the review of the existing studies, it is clear that there are a large number of factors that may affect the travelers' choices. However, researchers do not reach an agreement on which factors are the most important ones. This could be because that the interviewed people have financial statuses that are different or the survey locations have different geographical attributes. Alternatively, it may be because different methodologies were adopted to analyze the factors. However, several factors (including the travel time, trip cost, access time, and parking policies in the CBD) have been unequivocally demonstrated to influence the acceptance of P\&R by travelers. 
(ii) P\&R schemes have already been widely adopted in the USA, UK, as well as some other countries in Europe, Asia, and Australia. However, the impact of this kind of infrastructure on trip making and the acceptance of P\&R by travelers has not yet been clearly established. Although Hamer (2010) emphasized the need that the governments consider land use as well as the transport and parking policies holistically when planning $P \& R$ projects intended to improve the acceptance of $P \& R$ by travelers. However, he did not conduct further studies on the combined effect of these factors on travelers' acceptance.

In terms of the aforementioned limitations, this paper proposes a research methodology to explore the acceptance of P\&R by travelers. It firstly introduces the use of an SP method to enquire about users' travel preferences. And then, a cumulative logistic regression model to analyze the preferences is adopted. Finally, based on the practical case, it furnishes some useful insights into P\&R travel behavior to help authorities make appropriate policy choices.

The rest of the paper is organized as follows: the survey procedure is introduced in Section 2, Section 3 presents the cumulative logistic regression model employed, and discusses the regression analysis. The paper's conclusions are drawn in Section 4.

\section{Survey procedure}

\subsection{Survey method}

The questionnaire used in the field survey consisted of both revealed preference (RP) and SP questions. The RP component is intended to find out the existing choices and experiences of travelers using P\&R services. However, the SP component helps in the analysis of the prospective mode acceptance behavior of the travelers. The difference between the RP and SP interrogation methods is that the former type of questions is used to figure out what the respondents actually do in the real world, whereas the latter is used to predict what respondents will do under the supposed set of circumstances. As the data is collected according to what has happened during previous and ongoing trips in the real world (i.e., RP data), it is necessarily going to be more reliable than that collected using the SP approach. However, in order to get information about events that have not yet happened, SP data is essential as it can be used to make simulations. In other words, the data collected from SP surveys allows researchers to forecast the future trends (Hensher, Rose, \& Greene, 2005; Train, 2009). Another advantage of SP data is that it is flexible enough to allow researchers to evaluate all kinds of different underlying combinations of circumstances.

In this study, the survey questionnaire consisted of RP and SP questions, which is shown in Appendix. In the questionnaire, the socio-economic characteristics related to responses are asked: age, gender, annual income, education, employment status and car ownership. A summary of the RP questions is provided in the paper by Islam, Liu, Sarvi, and Zhu (2015). It mainly includes the destination of trip, purpose of this trip, travel time to this station, frequency of visiting this station, original travel modes, reasons for charging it to $P \& R$, acceptance levels to $P \& R$ in Melbourne, etc. (Islam et al. (2015) uses $\mathrm{RP}$ data to provide a basic understanding of the $\mathrm{P} \& \mathrm{R}$ behavior but does not give an in-depth quantitative analysis of the data, which is the objective of the current paper.) Before shifting towards $P \& R, 44 \%$ of travelers used driving alone mode, $19 \%$ of them used public transportation only. The convenient of travel and cheap price are the main reasons for their mode shifting. Besides, the long travel time happen at using public transport and transfer time at $P \& R$ station reduced travelers' enthusiasm to choose $P \& R$. The RP data showed that over $80 \%$ of the respondents thought that the traffic conditions in Melbourne were congested, and the PFs in the $\mathrm{CBD}$ are too high. However, the majority of respondents believed that the $P \& R$ stations are very conveniently located and the walking time to transfer to the $P \& R$ facilities is short. More than half of the respondents were satisfied with the public transport services. 
To analyze the factors influencing the mode choice of $\mathrm{P} \& \mathrm{R}$, some hypothetical scenarios are needed to be given. These transportation attributes for different trip modes include parking fare-PF in CBD, public transport total travel time-PTTT, transfer time-TT in the P\&R facility, etc. (Cheng, Chen, Bi, \& Yang, 2016; Cheng, Chen, Yang, Wu, \& Yang, 2017). In this paper, we developed 9 concrete scenarios in which each factor was exactly quantified. Respondents were asked to mark their willingness use the P\&R. We used a 5-point Likert scale to represent the preferences of the respondents.

An intercept interview approach was used at three railway stations, a garden location in the city, and a designated bus P\&R facility in Melbourne (Table 2). The distance from the CBD and the number of available parking space were taken into consideration when selecting the survey locations, which is an approach that proved useful in the paper by Islam et al. (2015). Participants were chosen on a first-come, first-served basis. They were approached with the questionnaire as soon as they alighted from the train and interviewed. Only those who responded were used to conduct the survey. The survey was conducted in April-May 2014, and a total of 1224 samples were collected.

Table 2. The survey locations used in the study

\begin{tabular}{lcc}
\hline Survey location (sample proportion) & Distance from CBD $(\mathrm{km})$ & Available parking spaces \\
\hline Doncaster (42.67\%) & 18 & 400 \\
Glen Waverley (23.53\%) & 24 & 340 \\
East Malvern (25.74\%) & 14 & 676 \\
Blackburn (2.94\%) & 22 & 112 \\
Huntingdale Station (0.74\%) & 20 & $\mathrm{n} / \mathrm{a}$ \\
Flagstaff Gardens (4.41\%) & 3 & $\mathrm{n} / \mathrm{a}$ \\
\hline
\end{tabular}

\subsection{Design of the SP survey}

In the SP part of the questionnaire, the following travel assumption was presented:

"Suppose you are travelling from a suburban area to the CBD of Melbourne. How likely would you be to choose P\&R based on these different combinations of total parking fare in the CBD (PF), public transport total travel time-PTTT and total transfer time spent at the P\&R station (TT)? Note that the TT equals the sum of parking time, walking time to the platform and waiting time for the train."

The three factors mentioned in the above question were chosen in accordance with the local context (i.e., they are considered to be the most influential factors with respect to these travelers' choice of daily travel mode). Each element involved three specified levels. The PF was set to AU\$10, AU\$20, or AU $\$ 40$ per day; PTTT (the time taken for the whole trip) to 40, 60, or $90 \mathrm{~min}$; and TT to 5, 10, or 20 min. The AU dollar (\$) to US dollar (\$) and EURO ( $€$ ) exchange rates are 0.69 and 0.61 as of June 16, 2019. All choices were made based on the assumption that all other factors remain the same. The combination of three different levels of three factors results in 27 possible scenarios $(3 \times 3 \times 3)$. Therefore, we adopted an orthogonal fractional factorial design consisting of 9 combinations to facilitate implementation of the questionnaire. For each scenario proposed, respondents were required to mark to what extent they would use the P\&R according to a 5-point Likert scale (Q2 in Appendix). The actual combinations corresponding to the 9 scenarios presented are shown in Section III in Appendix. 


\section{$3 \quad$ Model and data analysis}

\subsection{The cumulative logistic regression model}

The outcome variables used to analyze the data from the SP survey are categorized as ordinal choice variables. Discrete choice models, such as SLR, MNL, etc., are inappropriate because they ignore the fact that those variables are ordered, the giving results are inaccurate and lack of robustness $(\mathrm{Qu}$, Wang, \& Zhang, 2015). Therefore, in terms of the ordered outcomes, we adopt a statistical method, the cumulative logistic regression, to analyze the ordinal variables, which is different from the multinomial and nested logit models (Ji et al., 2017; Guo, Li, Wu, \& Xu, 2018a, 2018b). This method has many advantages, such as the simpler interpretation, greater detection power, and greater flexibility (Boisjoly, Wasfi, \& El-Geneidy, 2018). By using this method, we can analyze the relationships between the relevant factors and $P \& R$ acceptance more reasonably and deduce results that are more reliable. Those alternatives are not considered, like the private car, public transport and taxi. The main reason is that this paper focuses on the factors influencing users' choice under the different $P \& R$ scenarios. It is a common assumption in the SP survey that the response makes decisions with the given travel mode (Huang, Liu, Kim, Zhang, \& Zhu, 2019).

Furthermore, for each respondent, several hypothetical scenarios are given, in which 5 choices are listed. A 5-point Likert scale was proposed to measure the perception of passengers toward P\&R, in which " 1 " corresponds to "very unlikely" and " 5 " to "very likely." Unlike traditional interval cases, with ordered scales there exists a clear sequence of ordered levels, which means that the dependent variables are both discrete and ordinal. The model adopted is based on random utility theory and an ordered probit model. The more detailed explanation of these aspects is given in the following paragraphs.

Let $Z_{i j}$ represent the ordinal response for the $t$ th observation of the $i$ th respondent, where $T$ is the number of scenarios and $I$ is the set of respondents. $x_{i}$ are the explanatory variables of the $i$ th respondent and $u_{i}$ are its set of random effects. $y_{i}$ are the explanatory variables to the $t$ th observation and and $v_{i}$ are its set of random effects. Suppose the random effects $u_{i}$ and $v_{i}$ follow the normal distribution.

$$
P\left(Z_{i j}>\kappa \mid x_{i}, y_{t}, \kappa, u_{i}, v_{t}\right)=H\left(\beta_{0}+\beta_{1} x_{i}+\beta_{2} y_{t}+u_{i}+v_{t}+\varepsilon_{i t}\right)
$$

$H(\cdot)$ is the logistic cumulative distribution function.

The observed ordinal responses $Z_{i j}$ are generated from the latent continuous responses:

$$
Z_{i j}=\left\{\begin{array}{llr}
1 & \text { if } & Z_{i j}^{*} \leq \kappa_{1} \\
2 & \text { if } & \kappa_{1}<Z_{i j}^{*} \leq \kappa_{2} \\
& & \\
K & \text { if } & \kappa_{I-1}<Z_{i j}^{*}
\end{array}\right.
$$

\subsection{The cumulative logistic regression model}

The STATA statistical software package was adopted to estimate the parameters in the cumulative logistic regression model. Three socio-demographic attributes of the respondents of age, gender and income, and three factors of parking fare-PF, public transport total travel time-PTTT, and total transfer time-TT spent at $\mathrm{P} \& \mathrm{R}$ stations are taken as the independent variables. The survey results are presented in Table 3 and Table 4. For scenarios 2, 3, 4, 5, 6, and 8, the choice "Likely" is the highest, while in scenarios 1, 7 and 9 , most respondents choose "Very likely." 
Table 3. The socio-demographic attributes

\begin{tabular}{|c|c|c|c|c|c|}
\hline Attribute & \multicolumn{5}{|c|}{ Response } \\
\hline Gender & \multirow{2}{*}{\multicolumn{3}{|c|}{$\begin{array}{l}\text { Female } \\
46.98 \%\end{array}$}} & \multirow{2}{*}{\multicolumn{2}{|c|}{$\begin{array}{c}\text { Male } \\
53.02 \%\end{array}$}} \\
\hline Percentage & & & & & \\
\hline Age & $\begin{array}{l}\text { Less than } \\
18 \text { years }\end{array}$ & $18-25$ years & $26-35$ years & $36-50$ years & $\begin{array}{c}\text { More than } \\
50 \text { years }\end{array}$ \\
\hline Percentage & $0 \%$ & $19.85 \%$ & $16.18 \%$ & $36.03 \%$ & $27.94 \%$ \\
\hline Income & $\begin{array}{l}\text { Less than } \\
\$ 20,000\end{array}$ & $\$ 20,000-\$ 40,000$ & $\$ 40,001-\$ 60,000$ & $\$ 60,001-\$ 80,000$ & $\begin{array}{c}\text { More than } \\
\$ 80,000\end{array}$ \\
\hline Percentage & $12.03 \%$ & $9.77 \%$ & $18.05 \%$ & $29.32 \%$ & $30.83 \%$ \\
\hline
\end{tabular}

Table 4. The results for each of the SP scenarios

\begin{tabular}{c|ccccc}
\hline Scenario & & & Response & \\
& Very unlikely & Unlikely & Neutral & Likely & Very likely \\
\hline 1 & 2 & 2 & 6 & 48 & 78 \\
2 & 1 & 28 & 28 & 48 & 31 \\
3 & 3 & 17 & 18 & 56 & 42 \\
4 & 10 & 12 & 12 & 58 & 44 \\
5 & 3 & 12 & 23 & 58 & 40 \\
6 & 0 & 4 & 8 & 68 & 56 \\
7 & 1 & 3 & 8 & 50 & 74 \\
8 & 2 & 8 & 19 & 65 & 42 \\
9 & 1 & 7 & 12 & 52 & 64 \\
\hline
\end{tabular}

\subsection{Formulation and interpretation}

\section{(1) Parallel lines tests}

As mentioned previously, the basic assumption of the cumulative logistic regression model is that the independent variables exert the same influence on the dependent variable, i.e., the consequences of the same $\beta$ value. The model constructed satisfies the "parallel lines assumption" as the $p$-value is larger than 0.05 .

\section{(2) Modeling results and interpretation}

The results shown in Tables 5 indicate that the all total PF and total transfer time-TT spent at P\&R stations significantly affect the acceptance of $\mathrm{P} \& \mathrm{R}$ by respondents. More specifically (assuming the other variables are kept constant), for a unit increase in total PF (1 AU\$) in the city, the odds of the response "Very likely" (as opposed to the other categories "very unlikely," "unlikely," "neutral," and "likely") increases by $[\exp (0.039)-1] \times 100 \%=3.025 \%$. Similarly, for a unit increase in public transport total travel time-PTTT, the odds of a "Very likely" response increase by $[\exp (0.003)-1] \times 100 \%=0.3005 \%$. For a unit increase in total TT, the odds of the "Very likely" response decrease by $[1-\exp (-0.169)] \times 100 \%=$ $11.1837 \%$.

From the above analysis, it is clear to see that TT plays the most significant role in determining the respondents' preference. The next important factor is PF, and PTTT has the least impact on the acceptance of P\&R by travelers. Furthermore, the estimated value of the parameter for PF (0.0298) is 
positive, which means that when the other variables are kept constant, any increase/decrease in PF will cause an increase/decrease in the acceptance of P\&R. The estimated parameter for PTTT (0.0030) is also positive. However, the p-value is larger than 0.321. It indicates that the PTTT might be not significant in this study. In addition, the estimated parameter for TT $(-0.1186)$ is negative. This means that the increase/decrease in TT will decrease/increase the rate of acceptance of P\&R when the other variables remain constant.

Besides, we take the socio-demographic attributes $x_{i}$ into account, like Age and Gender. However, those selected attributes are not significant. The estimate of random-effects parameters in respondents are about 0.36 .

Table 5. Estimated parameter values

\begin{tabular}{lcccccc}
\hline & & Coef. $\beta$ & Std. error & $\mathrm{z}$ & Sig. & 95\% CI \\
\hline Threshold & {$[$ CHOICE $=1]$} & -6.5407 & 0.4277 & - & - & $(-7.3789,-5.7024)$ \\
& {$[$ CHOICE $=2]$} & -4.3823 & 0.3617 & - & - & $(-5.0912,-3.673)$ \\
& {$[$ CHOICE $=3]$} & -3.0135 & 0.3457 & - & - & $(-3.6910,-2.3359)$ \\
& {$[$ CHOICE $=4]$} & 0.2222 & 0.3302 & - & - & $(-0.4250,-0.8693)$ \\
\hline Factor $y_{i}$ & PF & 0.0030 & 0.0030 & 0.99 & 0.321 & $(-0.0029,0.0090)$ \\
& PTTT & -0.1186 & 0.0105 & -11.26 & 0.000 & $(-0.1392,-0.0980)$ \\
& TT & -6.5407 & 0.4277 & - & - & $(-7.3789,-5.7024)$ \\
\hline Random-effects Parameters & Estimate & & Estimate Std. Err. & \\
Respondent & & 0.3649 & & 0.0508 & & $(0.2777,0.4795)$ \\
Scenario & & 0.0070 & & 0.0051 & & $(0.0017,0.0293)$ \\
\hline
\end{tabular}

Note that in the survey questions, only three main explanatory variables are considered in the ordinal model, which are PTTT, TT and PF. These three factors are chosen as the most significant ones. As an initial step on the addressed topic, to focus on the three key factors is capable to handle for the survey conductors and also much clear to follow for the readers. It is a promising topic for a future work to further account for the other factors, including the road congestion level, station attributes, individual and household characteristics, etc.

\subsection{Policy implications}

It is difficult for the authorities to make obvious reductions in the TT at the P\&R facilities by taking engineering measures. The PTTT component is also not easy to control. Therefore, an effective way of maximizing the utilization of $\mathrm{P} \& \mathrm{R}$ facilities is to set reasonable PF levels in the CBD. A high parking fee in the CBD will lead to an increase in the mode share of P\&R. Furthermore, to facilitate the short transfer time, the urban land surrounding the $P \& R$ station should be able to meet the great demand placed on it (i.e., have enough land available nearby to house the public transport station and parking space for the privately-owned vehicles).

In summary, we find that travel time and travel cost always play the significant role to decide the use of $P \& R$ systems. Those factors affect each other. Users will weigh both them to make the decision to use $P \& R$ service. Besides, when installing the $P \& R$ stations, the location and accessibility should be taken into account by the organizer or the local government. However, there are some limitations in this paper. We focus on three main factors of PF, TT and PTTT, which are assumed as the important three factors to affect travelers' mode choice. Such an assumption may not reflect the reality. It ignores some transportation attributes. For example, the capacity of parking station plays the important role to design 
the P\&R station. The low convenient caused by the shortage of parking spaces would reduce the demand of using $P \& R$. The situation of road congestion and detour distance result in the increase of travel costs, which affects the mode choice of potential users. Besides, the characteristic of land use should be paid more attention when deciding the location of $P \& R$ station. Hence, to promote the development of sustainable transport systems, especially the $P \& R$, the local government should collect a great number of data related to traveler's mode choice, not just the PF and TT, PTTT.

\section{Conclusions}

Gaining public support is critical for successful implementation of a P\&R scheme. In order to understand which factors have the potentially significant influence on public support for $\mathrm{P} \& \mathrm{R}$, a paper-based survey was conducted in Melbourne, Australia. 9 hypothetical scenarios are provided to each respondent. For each scenario, the respondents' levels of support for $\mathrm{P} \& \mathrm{R}$ were measured on a 5-point Likert scale through a series of SP experiments. Based on the collected data, a two-level cumulative logistic regression model approach was applied to identify the significant factors and to quantify their relationship with the respondents' level of support for P\&R.

We find that the high parking fare-PF, long public transport total travel time-PTTT, and short transfer time-TT facilitate implementation of P\&R. However, the PTTT has the low significance. Based on the probability of each preferable choice, it demonstrates that the TT in the P\&R facilities is the most significant factor affecting the choice of $P \& R$. The PF constitutes a critical value when it comes to people deciding whether to use $P \& R$ facilities. The findings from this study will provide valuable guidance to policy makers tasked with developing effective strategies to promote P\&R usage. The density and accessibility of P\&R stations should consider the specific values of PF, TT, and PTTT in particular areas.

Although this paper has explored the acceptance of P\&R by users in-depth, there will inevitably be some improvements that may be made to increase its usefulness. For example, the number of factors influencing P\&R choice may help study the travelers' choices in the even greater depth. Also, in the SP survey of this paper, only the trips going to the central business district are covered, it is worthwhile to further strengthen the survey part by providing more general and heterogeneous questions/contexts. Besides, in this paper, a 5-point Likert scale was proposed that response can choose but they are supposed to take the P\&R as their travel mode. When carrying out the cumulative logistic regression, those alternatives are not taken into account. Actually, with such an assumption in SP survey, it is challenging to avoid that the responses may bias the P\&R. We hope to analyze the biased results caused by considering $P \& R$ and alternatives in future studies.

\section{Acknowledgements}

This study is supported by the General Projects (No. 71771050) and Key Projects (No. 51638004) of the National Natural Science Foundation of China, and the study is also supported in part by the Jiangsu Provincial Key Laboratory of Networked Collective Intelligence under Grant BM2017002. 


\section{References}

Boisjoly, G., Wasfi, R., \& El-Geneidy, A. (2018). How much is enough? Assessing the influence of neighborhood walkability on undertaking 10-minutes walks. Journal of Transport and Land Use, 11(1), 143-151.

Cheng, L., Chen, X., Bi, X., \& Yang, S. (2016). Exploring the impacts of location factors on the travel behavior of urban low-income residents in China. CICTP Proceedings, 2016, 2376-2389.

Cheng, L., Chen, X., Yang, S., Wu, J., \& Yang, M. (2017). Structural equation models to analyze activity participation, trip generation, and mode choice of low-income commuters. Transportation Letters, 11(6), 341-349.

Clayton, W., Ben-Elia, E., Parkhurst, G., \& Ricci, M. (2014). Where to park? A behavioral comparison of bus park and ride and city center car park usage in Bath, UK. Journal of Transport Geography, 36, 124-133.

Dijk, M., de Haes, J., \& Montalvo, C. (2013). Park-and-ride motivations and air quality norms in Europe. Journal of Transport Geography, 30, 149-160.

Duncan, M., \& Christensen, R. K. (2013). An analysis of park-and-ride provision at light rail stations across the US. Transport Policy, 25, 148-157.

Evans IV, J., \& Pratt, R. (2003). Traveler response to transportation system changes. Washington, DC: Transportation Research Board.

Guo, Y., Li, Z., Wu, Y., \& Xu, C. (2018a). Exploring unobserved heterogeneity in bicyclists' red-light running behaviors at different crossing facilities. Accident Analysis \& Prevention, 115, 118-127.

Guo, Y., Li, Z., Wu, Y., \& Xu, C. (2018b). Evaluating factors affecting electric bike users' registration of license plate in China using Bayesian approach. Transportation Research: Part F, 59, 212-221.

Hamer, P. (2010). Analyzing the effectiveness of park and ride as a generator of public transport mode shift. Road \& Transport Research, 19(1), 51-61.

Hamid, N. A., Mohammad, J., \& Karim, M. R. (2008). Travel behavior of the park-and-ride users and the factors influencing the demand for the use of the park-and-ride facility. Chemistry International, $37(2), 10-14$.

Hensher, D. A., Rose, J. M., \& Greene, W. H. (2005). Applied choice analysis: A primer. Cambridge, UK: Cambridge University Press.

Huang, K., Correia, G., \& An, K. (2018). Solving the station-based one-way carsharing network planning problem with relocations and non-linear demand. Transportation Research Part C, 90, 1-17.

Huang, K., Liu, Z., Kim, I., Zhang, Y., \& Zhu, T. (2019). Analysis of the influencing factors of carpooling schemes. IEEE Intelligent Transportation Systems Magazine. doi: 10.1109/MITS.2019.2919550

Islam, S. T., Liu, Z., Sarvi, M., \& Zhu, T. (2015). Exploring the mode change behavior of park-and-ride users. Mathematical Problems in Engineering, 2015, 1-8.

Ji, Y., Fan, Y., Ermagun, A., Cao, X., Wang, W., \& Das, K. (2017). Public bicycle as a feeder mode to rail transit in China: The role of gender, age, income, trip purpose, and bicycle theft experience. International Journal of Sustainable Transportation, 11(4), 308-317.

Karamychev, V., \& van Reeven, P. (2011). Park and ride: Good for the city, good for the region? Regional Science and Urban Economics, 41(5), 455-464.

Li, Z. C., Lam, W., Wong, S., Zhu, D. L., \& Huang, H. J. (2007). Modeling park-and-ride services in a multimodal transport network with elastic demand. Transportation Research Record, 1994, 101-109.

Lindstroem, A. (2003). Factors that influence choice of travel mode in major urban areas. The attractiveness of park \& ride (TRITA-INFRA, 48). Stockholm: Department of Infrastructure, Royal Institute of Technology. 
Liu, Z., Chen, X., Meng, Q., \& Kim, I. (2018). Remote park-and-ride network equilibrium model and its applications. Transportation Research: Part B, 117, 37-62.

Liu, Z., \& Meng, Q. (2012). Bus-based park-and-ride system: A stochastic model on multimodal network with congestion pricing schemes. International Journal of Systems Science, 45(5), 994-1006.

Liu, Z., Wang, S., Huang, K., Chen, J., \& Fu, Y. (2019). Practical taxi sharing schemes at large transport terminals. Transportmetrica B: Transport Dynamics, 7(1), 596-616.

Mahmoud, M. S., Habib, K. N., \& Shalaby, A. (2014). Park-and-ride access station choice model for cross-regional commuting: Case study of Greater Toronto and Hamilton area, Canada. Transportation Research Record, 2419(1), 92-100.

Mingardo, G. (2013). Transport and environmental effects of rail-based park and ride: Evidence from the Netherlands. Journal of Transport Geography, 30, 7-16.

Olaru, D., Smith, B., Xia, J. C., \& Lin, T. G. (2014). Travelers' attitudes towards park-and-ride (P\&R) and choice of P\&R station: Evidence from Perth, Western Australia. Procedia-Social and Behavioral Sciences, 162, 101-110.

Qin, H., Guan, H., \& Zhang, G. (2012). Analysis of the travel intent for park-and-ride based on perception. Discrete Dynamics in Nature \& Society, 2012, 2079-2092.

Qin, H. M., Guan, H. Z., \& Wu, Y. J. (2013). Analysis of park-and-ride decision behavior based on Decision Field Theory. Transportation Research: Part F, 18, 199-212.

Qu, X., Wang, S., \& Zhang, J., (2015). On the fundamental diagram for freeway traffic: A novel calibration approach for single-regime models. Transportation Research: Part B, 73, 91-102.

Shirgaokar, M., \& Deakin, E. (2005). Study of park-and-ride facilities and their use in the San Francisco bay area of California. Transportation Research Record, 1927, 46-54.

Train, K. E. (2009). Discrete choice methods with simulation. Cambridge, UK: Cambridge University Press.

Wang, S. (2013). Efficiency and equity of speed limits in transportation networks. Transportation Research: Part $C, 32,61-75$.

Wang, J. Y., Yang, H., \& Lindsey, R. (2004). Locating and pricing park-and-ride facilities in a linear monocentric city with deterministic mode choice. Transportation Research: Part B, 38, 709-731.

Yan, S., Delmelle, E., \& Duncan, M. (2012). The impact of a new light rail system on single-family property values in Charlotte, North Carolina. Journal of Transport \& Land Use, 5(2), 60-67.

Ying, H., \& Xiang, H. (2009). Study on influence factors and demand willingness of park and ride. 2009 Second International Conference on Intelligent Computation Technology \& Automation, 4, 664 667. doi: 10.1109/ICICTA.2009.874

\section{Appendix}

Appendix available as a supplemental file at www.jtlu.org/index.php/jtlu/rt/suppFiles/1390/0. 